\title{
An evaluation of patients' adherence with hypoglycemic medications among Papua New Guineans with type 2 diabetes: influencing factors
}

\author{
This article was published in the following Dove Press journal: \\ Patient Preference and Adherence \\ 16 September 2014 \\ Number of times this article has been viewed
}

\section{Stella Tilu Pihau-Tulo \\ Richard W Parsons \\ Jeffery D Hughes}

CHIRI and School of Pharmacy, Curtin University, Perth, WA, Australia
Correspondence: Jeffery D Hughes School of Pharmacy, Curtin University, GPO Box U1987, Perth, WA 6845, Australia

Tel +6I 892667367

Fax+6I892662769

Email j.d.hughes@curtin.edu.au
Purpose: The aims of this study were to evaluate the extent of adherence to hypoglycemic medications, assess the relationship between adherence and glycemic control, and evaluate factors affecting adherence.

Research design and methods: This was a cross-sectional study of patients with established type 2 diabetes attending the Port Moresby General Hospital Diabetes Clinic. Face-to-face interviews were conducted using a questionnaire designed for the study and data were collected concerning the 3 months prior to interview. The questionnaire covered demographic details, lifestyle, biochemical and physical measurements, and medication management. Glycemic control was investigated among patients adhering to their medications (not missing doses) to different degrees $(100 \%, 95 \%, 90 \%$, and $80 \%)$.

Results: Of a total of 356 participants who were prescribed hypoglycemic medications, $59.6 \%$ omitted some of their doses. Age appeared to have a significant impact on adherence at some levels of adherence, with those aged $>60$ years being more likely to be adherent (logistic regression). Those who were $95 \%-99 \%$ and those who were $<80 \%$ adherent had a statistically significant risk of a high glycated hemoglobin of $>10 \%(85.5 \mathrm{mmol} / \mathrm{mol})$. Multiple factors were identified as contributors to nonadherence, with patient-based issues $(86.0 \%)$ and the health care system $(21.7 \%)$ being the most common.

Conclusion: This study showed a significant level of nonadherence among patients with type 2 diabetes in Papua New Guinea. Nonadherence to medication appeared to be associated with poor glycemic control and was due to a variety of reasons. Future interventions aimed at improving adherence will need to take these into account.

Keywords: adherence, type 2 diabetes, A1C, Papua New Guinea, age, sex, contributing factors

\section{Introduction}

The World Health Organization (WHO) reports that there are 347 million people living with diabetes worldwide and, of these, more than $80 \%$ live in low- and middleincome countries. ${ }^{1}$

Papua New Guinea (PNG) is a lower-middle-income country where diabetes is increasing. The earliest report of diabetes in PNG was in 1963, where 10 cases were seen at the Port Moresby General Hospital (PMGH) over a 3-year period. ${ }^{2}$ The first survey of diabetes in 1962 found no cases in a rural district and a $0.2 \%$ prevalence in four suburban communities in Port Moresby. ${ }^{3}$ The diabetes prevalence in various coastal population groups in PNG have been reported to range from $0.2 \%$ in the $1960 \mathrm{~s}$ to $33.0 \%$ in the $1990 \mathrm{~s}^{3-7}$ A survey in two highlands populations in 1983 and 1985 reported a complete absence of diabetes as well as impaired glucose tolerance prevalence rates ranging from $1.7 \%-2.7 \%$. $^{6,8}$ The WHO reported 
in 2000 that PNG had 152,000 cases of diabetes, ${ }^{9}$ while the International Diabetes Federation in 2013 reported the number of cases to be $203,000 .{ }^{10}$ Furthermore, the WHO has estimated that the number of cases of diabetes will increase to 392,000 by $2030 .{ }^{9}$ PNG has a population of 7 million and the national prevalence of diabetes in adults aged 20-79 year reported by International Diabetes Federation in 2013 was $5.4 \% .^{10}$

The increasing prevalence of type 2 diabetes in PNG will lead to a significant economic burden because of increased health care costs incurred from hospitalizations and associated costs, clinic visits, and use of medicines, not only for persistent hyperglycemia but also for complications of diabetes. Poor self-management of drug therapy by patients with diabetes may worsen the burden of diabetes in PNG.

Studies linking glycemic control, hypoglycemic medications, and complications of diabetes have shown that good glycemic control is important in preventing microvascular complications of this condition. ${ }^{11-13}$ A study in PNG showed that, over a 1 -year period, $64 \%$ of the 83 patients with diabetes showed poor glycemic control (glycated hemoglobin $[\mathrm{A} 1 \mathrm{C}]>10.0 \%[85.8 \mathrm{mmol} / \mathrm{mol}]) .{ }^{14}$ To the best of our knowledge, no recent studies have been published on glycemic control among Papua New Guineans with type 2 diabetes.

One of the challenges in achieving good glycemic control is patients' nonadherence to their medications. Nonadherence to medications for chronic diseases such as diabetes is a complicated and dynamic problem that can seriously affect patient outcomes.

Using different definitions and methodologies to assess medication adherence, studies have reported adherence rates to oral hypoglycemic medications ranging from $36 \%-93 \%$ in patients with type 2 diabetes. ${ }^{15-19}$ A number of studies have reported different factors that contribute to nonadherence with hypoglycemic medications.

Many other studies have reported medication adherence challenges in different countries or populations; however, this is the first study that investigates the issue in PNG specifically.

The consequences of diabetes in a vulnerable country like PNG are expected to be devastating in their demand on the health care system. Even at present, the PNG health care system does not have sufficient resources to provide adequate support to patients with diabetes and other chronic illnesses. In the future, the health services are expected to be pushed well beyond capacity to deal with this emerging epidemic.

\section{Research design and methods Study design}

Cross-sectional study.

\section{Setting}

PMGH, PNG.

\section{Participants}

All patients who were diagnosed with type 2 diabetes and were registered at the PMGH Diabetes Clinic for at least 3 months were considered for inclusion. This ensured that recently diagnosed subjects were excluded from study, as the main outcomes concerned adherence and glucose control over the 3 months leading up to enrollment in the study. All patients in the appointment book were identified as potentially eligible participants. The registration book was used to confirm date of diagnosis.

Patients diagnosed with HIV/AIDS, pregnant women, and those using a wheelchair were excluded from the study. Those requiring a wheelchair were excluded because the broader study required physical measurements that were difficult to obtain for these patients. Eligible patients were informed of the study and invited to participate; those who agreed to do so provided written informed consent.

\section{Data collection}

The survey tool used was developed from the WHO STEPwise approach to Surveillance of non-communicable diseases (STEPS) instrument. ${ }^{20}$ Questions on medication were specifically included as well as details such as: year of diabetes diagnosis; initial management of diabetes; and management over the 3 months leading up to recruitment in the study. Questions on management of diabetes included whether or not the patient was put on a prescribed diet, hypoglycemic agent(s) and co-medications, lifestyle modifications, and any other forms of diabetes management.

\section{Demographic information}

Basic demographic data included sex, age, and area of residence. For the purposes of this study, area of residence was classified as: urban, peri-urban, rural, or other province. The urban dwellers were those who were living in urbanized suburbs within the city; peri-urban were those living in partly urbanized villages between the city suburbs and the rural villages within the outskirts of the city; rural dwellers were those living in rural villages in the Central Province; and dwellers in other provinces were those who lived outside of the National Capital District and Central Province. 


\section{Medication adherence}

Patients were interviewed to identify if they had missed any diabetic medication doses over the immediately preceding 3 -month period. The number of doses omitted for each hypoglycemic medication, frequency of omitting doses, and the reasons for omitting doses were documented. Analysis focused on adherence and the key factors influencing adherence. Glycemic control was examined at four different thresholds of adherence, namely $100 \%$ (complete adherence with treatment), $95 \%, 90 \%$, and $80 \%$. Percentage adherence was calculated by using the number of doses used in the 3 months as the numerator and the total number of prescribed doses for the 3 months as the denominator. Comments regarding the reasons for nonadherence were reviewed by the primary investigator and main themes were identified (qualitative analysis).

\section{Glycemic control}

Each patient's A1C level was measured following the interview using a Point-of-care Siemens/Bayer DCA 2000 Vantage $^{\mathrm{TM}}$ AIC analyser (Siemens Medical Solutions USA Inc, Malvern, PA, USA).

\section{Ethics}

Ethics approval to conduct this study was provided by the Curtin University Human Research Ethics Committee, the University of PNG, School of Medicine and Health Sciences Research and Ethics Committee, and the PNG Department of Health Medical Research Advisory Committee. Permission to undertake the study at the PMGH was granted by the hospital management.

\section{Data analysis}

Data were entered into an Excel dataset (Microsoft Corporation, Redmond, WA, USA), and transferred into the SAS version 9.2 statistical software (SAS Institute Inc., Cary, NC, USA) for analysis. Simple descriptive statistics were used to summarize the profile of study participants. Percentages of patients who were classified as nonadherent to medication within each subgroup - defined by their sex, age, and medication - were compared using the chi-square test, independent sample $t$-test, or the Wilcoxon two-sample test as appropriate. Glycemic control (assessed using the level of A1C) was calculated and tabulated against the adherence to treatment. A logistic regression model was developed to identify which (if any) of the demographic/medical profile variables were independently associated with nonadherence. All the profile variables were initially included as covariates, then dropped, one at a time, until all variables remaining in the model were associated with adherence (backwards elimination strategy). Results of this regression were presented as odds ratios (ORs), their $95 \%$ confidence intervals (CIs), and $P$-values. A logistic regression model was also developed to assess the influence of different levels of adherence on the A1C measurement Following convention, a $P$-value $<0.05$ was taken to indicate a statistically significant association in all tests.

\section{Results}

Three hundred and eighty-five patients with diabetes were recruited to the study. Twenty-nine of them were not taking any hypoglycemic medications (diet controlled only) and were excluded from the analysis. Among the remaining 356 participants, 144 (40.4\%) reported that they did not omit any doses, while the remaining 212 (59.6\%) reported omitting some of their doses. Of these 212 participants, five had ceased taking their medications for more than 3 months and were excluded from the study, and a further six could not remember how many doses they omitted. These six participants were included in the analyses of those who were known to have omitted some doses, as well as the analysis of the qualitative data examining factors contributing to omission of doses. However, they were excluded from analyses of those who omitted $>5 \%,>10 \%$, and $>20 \%$ of doses, as their exact percentages of missing doses was not known. Table 1 shows the characteristics of the participants included in the study. $P$-values in the table compare the adherence rates (complete adherence versus missing some doses) between different personal characteristics. The median (range) for: age was 55 (14-85) years; duration of disease for all participants was $5(0-30)$ years; doses per day of all medications was four (one to 12); tablets per day was five (one to $20)$; and baseline A1C was $8.7 \%$ (4.9\% to $>14.0 \%)$. Mean age appeared to differ significantly between those who adhered to their medications (57 years) and those who missed some doses ( 53 years, $P=0.0036$ ). The comparison of $\mathrm{A} 1 \mathrm{C}$ between those who were adherent and those who were nonadherent also appeared to differ, whether compared in categories (Table 1) or comparing means ( $8.8 \%$ versus $9.4 \%$, respectively, $P=0.0131$ ). The comparison of median $\mathrm{A} 1 \mathrm{C}$ measurements was of borderline significance $(P=0.0546)$. The majority of participants were female and dwelt in urban or peri-urban areas.

A total of 345 participants were included in the analysis using $80 \%, 90 \%$, and $95 \%$ as cut-offs for adherence, while 351 participants were included in the analysis when adherence was defined as not missing any hypoglycemic doses and when evaluating factors influencing adherence.

Univariate analysis of sex, area of residency, number of hypoglycemic agents, number of comedications, duration 
Table I Participant characteristics

\begin{tabular}{|c|c|c|c|}
\hline Variable & Frequency $^{\mathrm{a}} \mathbf{N}(\%)$ & Nonadherent ${ }^{\mathrm{b}} \%$ & $P$-value ${ }^{c}$ \\
\hline Sex & & & 0.9004 \\
\hline Female & $222(63.2)$ & 59.0 & \\
\hline Male & $129(36.8)$ & 59.7 & \\
\hline Age group & & & $0.024 I$ \\
\hline$\leq 50$ & II4 (33.7) & 65.8 & \\
\hline $5 I-60$ & $132(39.1)$ & 62.1 & \\
\hline$\geq 6 \mathrm{I}$ & $92(27.2)$ & 47.8 & \\
\hline Area of residence & & & 0.3320 \\
\hline Urban & $199(56.9)$ & 61.3 & \\
\hline Peri-urban & $67(19.1)$ & 62.7 & \\
\hline Rural village & $70(20.0)$ & 52.9 & \\
\hline Outside province & $14(4.0)$ & 42.9 & \\
\hline Number of hypoglycemic agents & & & 0.1702 \\
\hline 1 & I $87(54.0)$ & 55.6 & \\
\hline 2 or 3 & $159(46.0)$ & 62.9 & \\
\hline Number of comedications & & & 0.3530 \\
\hline 0 & $131(37.3)$ & 64.1 & \\
\hline 1 & $119(33.9)$ & 59.7 & \\
\hline 2 & $60(17.1)$ & 53.3 & \\
\hline$\geq 3$ & $4 I(I I .7)$ & 51.2 & \\
\hline AIC at baseline & & & 0.0105 \\
\hline$\leq 7 \%(53.0 \mathrm{mmol} / \mathrm{mol})$ & $63(18.9)$ & 55.6 & \\
\hline$>7 \%-10 \%(85.8 \mathrm{mmol} / \mathrm{mol})$ & $164(49.1)$ & 53.1 & \\
\hline$>10 \%$ & $107(32.0)$ & 71.0 & \\
\hline
\end{tabular}

Notes: $\mathrm{N}=351$. a May not add up to the total because of missing data. "Numbers in the "Nonadherent" column show the percentage of each row who were not completely $(100 \%)$ adherent to their medications. ${ }^{C} P$-values are calculated from the chi-square statistic.

Abbreviation: AIC, glycated hemoglobin.

since disease diagnosis, average number of doses, and tablets per day of all medications showed that none of these variables appeared to be associated with adherence at any level. Table 2 shows the results of the multivariate logistic regression modeling procedure applied to the data for different levels of adherence. Age appeared to be associated with adherence at some levels of adherence, with the older subjects ( $>60$ years) being more likely to be adherent than their younger counterparts. This association was not statistically significant for all levels of adherence, but showed a clear association at $100 \%$ adherence $(P=0.008)$, and a weaker $(P=0.035)$ association at $90 \%$. A separate logistic regression model was used to identify any association between adherence and high $\mathrm{A} 1 \mathrm{C}$, using $\mathrm{A} 1 \mathrm{C}>10 \%(85.5 \mathrm{mmol} / \mathrm{mol})$ as the dependent variable (Table 3 ). ORs for the adherence level were expressed relative to the completely adherent subjects. This analysis showed explicitly that the odds of high A1C was greater than 1 for all levels of nonadherence, but only significantly higher for the adherence levels of $95 \%-99 \%$ and $<80 \%$ (larger numbers of participants). Using A1C $>7.0 \%$ $(53.0 \mathrm{mmol} / \mathrm{mol})$ as the dependent variable, those aged $<60$ years tended to have poorer control than their older counterparts, but this did not reach statistical significance (crude $\mathrm{OR}=1.62,95 \% \mathrm{CI}=0.94-2.80, P=0.084)$. However, those aged 50 years or younger were found to be twice as likely to have poor glycemic control compared to those aged 50 years or older (crude OR $=2.18,95 \% \mathrm{CI}=1.19-4.01, P=0.012$ ).

The most common reasons cited by participants for omitting hypoglycemic doses were patient-related issues (86.0\%). These included forgetting doses (35.7\%), patients not refilling prescriptions (32.4\%), and patients refusing to take their hypoglycemic medications (10.6\%). The next most important factors cited were health-care-system related (21.7\%). Access to the diabetes clinic for repeat prescriptions was the most common issue of this type identified (15.9\%, Table 4).

\section{Discussion}

Adherence to medications is of paramount importance because there are strong correlations between medication adherence, patient outcomes, and treatment costs. ${ }^{21-23}$ Omission of medication doses is the most common type of nonadherence. ${ }^{24}$ This may be intentional or unintentional. This study evaluated omission of hypoglycemic medications and investigated reasons why patients omit their doses.

A high proportion of participants (59.6\%) reported omitting at least some of their doses. This is consistent with the trends that have been reported elsewhere. ${ }^{15-19}$ Studies 
Table 2 Multivariate logistic regression with nonadherence as the dependent variable

\begin{tabular}{|c|c|c|c|c|}
\hline Variable & Nonadherence $\mathrm{n} / \mathrm{N}$ (\%) & Odds ratio & $\mathbf{9 5} \%$ confidence interval & $P$-value \\
\hline \multicolumn{5}{|c|}{$100 \%$ adherence } \\
\hline \multicolumn{5}{|c|}{ Age } \\
\hline$>60$ & $5 \mathrm{I} / 105(48.6)$ & I (reference) & & \\
\hline$\leq 60$ & $157 / 246(63.8)$ & 1.87 & I.18-2.97 & 0.0081 \\
\hline \multicolumn{5}{|c|}{$95 \%$ adherence } \\
\hline \multicolumn{5}{|c|}{ Age } \\
\hline$>60$ & $27 / 104(26.0)$ & I (reference) & & \\
\hline$\leq 60$ & $77 / 24$ I (32.0) & 1.34 & $0.80-2.24$ & 0.2669 \\
\hline \multicolumn{5}{|c|}{$90 \%$ adherence } \\
\hline \multicolumn{5}{|c|}{ Age } \\
\hline$>60$ & I3/104 (I2.5) & I (reference) & & \\
\hline$\leq 60$ & $54 / 24 I(22.4)$ & 2.02 & $1.05-3.89$ & 0.0353 \\
\hline \multicolumn{5}{|c|}{$80 \%$ adherence } \\
\hline \multicolumn{5}{|l|}{ Age } \\
\hline$>60$ & $9 / 104$ (8.7) & I (reference) & & \\
\hline$\leq 60$ & $38 / 24 I(I 5.8)$ & 1.98 & $0.92-4.25$ & 0.0815 \\
\hline
\end{tabular}

have shown that nonadherence to medications leads to poor glycemic control ${ }^{25-28}$ but, unlike serious conditions such as HIV infection, there has not been agreement on what constitutes clinically adequate medication adherence in type 2 diabetes. Many studies have used the $80 \%$ and $90 \%$ cut-off to indicate adequate adherence. One argument for a cut-off point of $80 \%$ is the observation that the rate of hospitalization increased as the adherence scores fell below this threshold..$^{29}$ In our study, different cut-offs for adherence were used to determine their impact on glycemic control. Missing any doses appeared to be associated with a very high A1C measurement (A1C $>10 \%$ [85.8 $\mathrm{mmol} / \mathrm{mol}]$ ).

Sex did not appear to be associated with adherence in this study. This is consistent with other studies. ${ }^{17,30,31}$ Raum et al however, showed sex-specific differences in the association of adherence and poor glycemic control..$^{32}$ Their study $^{32}$ showed that there were only marginal differences in adherence between men and women, but nonadherent men carried double the risk of poor glycemic control compared to adherent men. Adherent and nonadherent women, however, did not differ significantly in regard to poor glycemic control.
Only three hypoglycemic medications are available through the public health care system in PNG - these are glibenclamide, metformin, and insulin. This number is limited because the list of medicines purchased is based on the WHO Model List of Essential Medicines, which is used to ensure affordable medicines are widely available. Usage of insulin in PNG is limited by requirements for its storage. As seen in this study, about $20 \%$ of participants live in the rural areas and $20 \%$ live in peri-urban areas. In rural PNG, only a few homes have portable electricity generators, but electricity is mostly for smaller appliances and lighting purposes only. Some peri-urban areas may not have consistent electricity supplies and, in particular, may not have refrigerators.

There is evidence that strong psychosocial support improves medication adherence. ${ }^{33}$ Participants in this study live in a society where extended families usually live in the one house. Family ties are strong and, usually, younger family members care for their elder relatives in the family home. The strong psychosocial support in a PNG society may have contributed to the finding that medication burden (number of hypoglycemic agents, number of comedications, average number of doses, and tablets per day of all medications) did

Table 3 Logistic regression analysis: the influence of medication adherence on abnormally high AIC

\begin{tabular}{lllll}
\hline Adherence level & AIC $>\mathbf{I 0} \% \mathbf{~} / \mathbf{N}(\%)^{\mathbf{a}}$ & Odds ratio & 95\% confidence interval & $P$-value \\
\hline $100 \%$ & $31 / 136(22.8)$ & 1 (reference) & & 0.0032 \\
$95 \%-99 \%$ & $38 / 92(41.3)$ & 2.4 & 1.3 to 4.2 & 0.1970 \\
$90 \%-94 \%$ & $12 / 36(33.3)$ & 1.7 & 0.8 to 3.8 & 0.4030 \\
$80 \%-89 \%$ & $6 / 19(31.6)$ & 1.6 & 0.5 to 4.5 & 0.0129 \\
$<80 \%$ & $19 / 45(42.2)$ & 2.5 & 1.2 to 5.1 & \\
\hline
\end{tabular}

Notes: Each participant was classified into their level of adherence, and the dependent variable was high AIC (AIC >I0\% [85.8 mmol/mol]). ${ }^{\mathrm{a} T h e}$ column showing " $\mathrm{n} / \mathrm{N}$ (\%)" shows the number of people (and percentage) within the given adherence level who have high AIC. Abbreviation: AIC, glycated hemoglobin. 
Table 4 Identified number of factors contributing to nonadherence

\begin{tabular}{ll}
\hline $\begin{array}{l}\text { Individual factors influencing } \\
\text { adherence }\end{array}$ & $\begin{array}{l}\text { Percentage } \\
\mathbf{n}(\%) \mathbf{( N = 2 0 7 )}\end{array}$ \\
\hline Patient-related factors & $74(35.7 \%)$ \\
$\quad$ Forgetting & $67(32.4 \%)$ \\
Had script but did not refill & $22(10.6 \%)$ \\
Refused to take hypoglycemic medications & $15(7.2 \%)$ \\
Others & \\
(Travel, transport costs to and from & \\
remote villages to the city, alternative & \\
therapy, lack of psychosocial support) & \\
Medication related factors & $15(7.2 \%)$ \\
$\quad$ Medication cost & $12(5.8 \%)$ \\
Perceived adverse effects & \\
Health care-system-related factors & $5(2.4 \%)$ \\
Access to and from remote villages & $7(3.4 \%)$ \\
Inconsistent medical supplies in public & \\
hospital & $33(15.9 \%)$ \\
Access to diabetes clinic for repeat & \\
scripts & \\
Prescriber factors & \\
Insufficient information about disease and & \\
medications & $4(1.9 \%)$ \\
Other reasons & \\
Theft of bag containing medications & \\
\hline
\end{tabular}

Note: ${ }^{\text {TTotal }}$ percentage $>100 \%$ because some participants gave more than one reason.

not affect adherence. However, some studies carried out in societies that are different to that of PNG have also found that a high medication burden or polytherapy may not contribute to medication nonadherence. ${ }^{25,26,30}$ This lack of association may not be consistent across all populations, as other studies have shown that a high medication burden is related to low levels of medication adherence. ${ }^{24,34}$ With the advantage of strong psychosocial support in PNG, patients and their family carers may need to develop good routines in medication behavior as it has been shown that developing such routines usually leads to higher levels of adherence. ${ }^{33}$

Younger people tend to have other priorities in their lives and lead busier lives than the elderly, due to employment and other social activities. This may partly explain why the younger age group was less adherent to their hypoglycemic medications than the older age group in this study. Older people may have also been more adherent in this study population because the study setting has a medication supply policy that exempts those aged 60 years and older from medication fees. Furthermore, care of the elderly in a single household where extended family usually live in a society like that in PNG may have led to better adherence in those aged 60 years and older. This finding that older people are more adherent is consistent with other studies that have shown that better hypoglycemic medication adherence is associated with increased age. ${ }^{18,35,36}$ Furthermore, studies in societies like that in PNG, where the elderly are cared for in homes where extended families reside, have also shown that older people have better glycemic control than their younger counterparts. ${ }^{19,37,38}$ These results, however, differ from the Scottish study, which found that younger patients had better adherence to their hypoglycemic medications. ${ }^{34}$ Interestingly, Nagrebetsky et al claimed that better glycemic control in older patients is to do with lower body mass index rather than good adherence. ${ }^{39}$

Our study showed that only a small number of participants (average of $18.3 \%$ ) achieved the optimal target glycemic control of $\leq 7.0 \%(53.0 \mathrm{mmol} / \mathrm{mol})$. This is slightly less than that seen in a Malaysian study population, ${ }^{40}$ but much less than that seen in Nigeria. ${ }^{41}$ A meta-analysis of data from 12 Asian countries $^{42}$ showed that $45 \%$ of the populations studied had A1C $\leq 8.0 \%$ (63.9 mmol $/ \mathrm{mol})$. An earlier study ${ }^{14}$ in PNG showed that $64 \%(\mathrm{~N}=83)$ had poor glycemic control (A1C $>10.0 \%$ $[85.8 \mathrm{mmol} / \mathrm{mol}])$. Our study suggests that missing any dose has a negative impact on glycemic control, which suggests that attainment of the highest possible adherence rate is important in this study population. Several earlier PNG studies have shown high morbidity and mortality associated with complications of diabetes; ${ }^{43,44}$ however, current studies in PNG in this area are lacking. Achieving good glycemic control is important to reduce such morbidities and mortalities. Studies in the US have shown that improved glycemic control is beneficial to patients with type 2 diabetes and, in general, conclude that every percentage point reduction in $\mathrm{A} 1 \mathrm{C}$ can reduce the risk of microvascular complications such as kidney diseases, eye diseases, and neuropathies by $40 \%{ }^{45}$

The most common reasons cited by participants for omitting doses were patient and health care-system related. The most common patient-related reason for omitting doses cited by participants was that patients forgot to take their medications. This is similar to a Hungarian study that showed that $44.6 \%$ of participants forgot to take their medications. ${ }^{46}$ The next most common patient-related factor was participants not refilling their medications despite having prescriptions. This group of participants did not elaborate further on their reasons for not doing so.

All participants who had problems with access to the diabetes clinic reported that they were waiting for their next medical review to pick up their new prescriptions. This led to them not continuing their medications as required. The contributing factors to this are: increase in the number of patients attending the clinic; scheduling of appointments; the number of clinic days and hours per week; cancellation/rescheduling of clinic times; shortage of staff at the clinic; and closure of the clinic from the beginning of December to the end of January 
every year. Scheduling of review dates for each individual patient depends on availability of an appointment time. Even if a doctor wants to see a patient 1 month later, for example, the next available appointment may not be until 2 weeks after that. This may lead to a patient missing out on their medications for 2 weeks, because the doctor will usually prescribe 1 month's supply of medication with the understanding that the patient will be seen again after a month. Despite the increase in the number of people diagnosed with diabetes, the clinic is still only open for 3 hours per week. To make matters worse, shortage of staff (both nursing and medical) often leads to cancellation or scaling down of the clinic.

Cost of medications is a crucial issue in medication adherence, especially for those who have been diagnosed with chronic diseases like type 2 diabetes, because therapy is ongoing (lifelong). A further cost burden is often incurred due to the complications associated with diabetes. Most patients in PNG do not have private medical insurance, but all patients benefit from subsidized medications through the public health system. Despite minimal medicine costs, many patients still cannot afford medications. There are also associated costs such as consultation fees and cost of transport to the clinic. Almost $20 \%$ of the participants in this study lived in rural villages where the cost of transport is even more than the cost of medicines. Apart from transport costs, those who live in the rural areas have to find accommodation in the city where the diabetes clinic is. Studies elsewhere have shown that cost of medications contributes to reduced adherence. ${ }^{38,41,47}$ The inconvenience of travel and the cost of travel also play a role.

There are three main policies that affect access to hypoglycemic medications in PNG. Hypoglycemic medications are only available in hospitals, which makes access more expensive for those living in rural villages. Another policy involves pharmacy fee exemptions. Patients with chronic diseases such as cardiovascular diseases and asthma are exempted from paying for their disease-related medications, but the same facility is not available in general for patients with diabetes. The exception is that patients who are 60 years and older are exempted from costs for all medical problems. This policy may need revising to improve adherence to hypoglycemic medications. The third policy is to do with the total quantities dispensed per patient. Pharmacy departments usually only dispense 1-month's supply, even if the prescriber makes a request for 3-months' supply, for example. Patients are then required to travel to the hospital pharmacy for their monthly refills.

There are limitations of this study method. One is that patients may have reported an overly optimistic estimation of adherence and, secondly, there may have been inaccurate patient recall of when and/or how many doses were missed.
It was not possible to validate adherence through pill counts; however, nonadherence could be validated through extended duration between clinic visits. Furthermore, this study did not investigate the impact of hypoglycemic dosage on glycemic control. The generalizability of our results to other diabetes care facilities with limited care, such as those in PNG and the region in general, may be limited as this study was in a highly specialized setting.

\section{Conclusion and recommendations}

This study showed a significant level of nonadherence (59.6\%) among patients with type 2 diabetes in PNG, and that poor adherence is associated with poor glycemic control. The most important predictor of adherence was found to be the patient's age, with those $<60$ years old appearing to be less adherent to treatment than their older counterparts. However, many factors were found to contribute to nonadherence, with patient-based issues $(86.0 \%)$ and the health care system $(21.7 \%)$ being the most common. Therefore, any future interventions aimed at improving adherence will need to take these into account.

To improve adherence among Papua New Guineans with type 2 diabetes, availability of diabetes medicines at all times and at sites other than diabetes clinics would be extremely useful. In terms of health care settings, improving access to the diabetes clinic, which may mean a separate diabetes clinic instead of co-sharing with other internal medicine specialties, may improve medication adherence, especially through access to new prescriptions and longer consultation times when required. Furthermore, diabetes patients may have to be exempted from pharmacy fees, as is the case for patients with cardiovascular diseases and asthma. Addressing patient-related factors may include involving family during patient education sessions about medications and diabetes, or conducting educational and training programs outside of the clinic days. It would also be useful to involve those who have lived with diabetes for an extended duration to share their experiences with those who have been recently diagnosed with diabetes. Such programs are not currently available in PNG. Tools such as mobile phone reminder alarms may also be useful in reminding patients to take their medicines. PNG patients have an advantage of living in a society where the elderly are cared for by their extended family, which may lead to the development of good routines in medication behavior that improve medication adherence. ${ }^{33}$

\section{Acknowledgments}

The collection of data was made possible by Dr Lloyd Ipai and his staff at the Diabetes Clinic, Port Moresby General 
Hospital in Papua New Guinea. We are also grateful to Beulah Sipana, George Gani, and Barbara Angoro for assistance in collecting data.

\section{Disclosure}

The authors report no conflicts of interest in this work.

\section{References}

1. www.who.int [homepage on the Internet]. Facts and figures about diabetes. World Health Organization; 2011 [updated October 2013; cited January 9, 2014]. Available from: www.who.int/mediacentre/ factsheets/fs312/en/. Accessed December 15, 2013.

2. Campbell CH. Diabetes Mellitus in the Territory of Papua and New Guinea. Med J Aust. 1963;2:607-610.

3. Hingston RG, Price AVG. Diabetic surveys in Papua. P N G Med J. 1964;7:33-35.

4. Price AV, Tulloch JA. Diabetes mellitus in Papua and New Guinea. Med J Aust. 1966;2:645-648.

5. Martin FI, Wyatt GB, Griew AR, Haurahelia M, Higginbottom L. Diabetes mellitus in urban and rural communities in Papua New Guinea: Studies of prevalence and plasma insulin. Diabetologia. 1980; 18(5):369-374.

6. King H, Finch C, Collins A, et al. Glucose tolerance in Papua New Guinea: ethnic differences, association with environmental and behaviour factors and the possible emergence of glucose intolerance in a highland community. Med J Aust. 1989;151(4):204-210.

7. Dowse GK, Spark RA, Mavo B, et al. Extraordinary prevalence of non-insulin-dependent diabetes mellitus and bimodal plasma glucose distribution in the Wanigela people of Papua New Guinea. Med J Aust. 1994;160(12):767-774.

8. King H, Heywood P, Zimmet P, et al. Glucose tolerance in a highland population in Papua New Guinea. Diabetes Res. 1984;1(1):45-51.

9. www.who.int [homepage on the Internet]. Diabetes Program. Facts and figures about diabetes. Country and regional data on diabetes. WHO Western Pacific Region, WHO Media Centre; 2014 [cited 2014 May 20]. Available from: www.who.int/diabetes/facts/world_figures/ en/index6.html. Accessed May 20, 2014.

10. www.idf.org [homepage on the Internet]. Diabetes facts and figures. International Diabetes Federation; 2014 [cited 2014 May 23]. Available from: www.idf.org/membership/wp/papua-new-guinea. Accessed May 20, 2014.

11. No authors listed. Intensive blood-glucose control with sulphonylureas or insulin compared with conventional treatment and risk of complications in patients with type 2 diabetes (UKPDS 33). UK Prospective Diabetes Study (UKPDS) Group. Lancet. 1998;352(9131):837-853.

12. No authors listed. Effect of intensive blood-glucose control with metformin on complications in overweight patients with type 2 diabetes (UKPDS 34). UK Prospective Diabetes Study (UKPDS) Group. Lancet. 1998;352(9131):854-865.

13. ADVANCE Collaborative Group, Patel A, MacMahon S, et al. Intensive blood glucose control and vascular outcomes in patients with type 2 diabetes. N Engl J Med. 2008;358(24):2560-2572.

14. Erasmus RT, Sinha AK. Assessment of long-term glycaemic control in diabetic patients attending Port Moresby General Hospital. $P N G$ Med J. 1995;38(1):16-19.

15. Cramer JA. A systematic review of adherence with medications for diabetes. Diabetes Care. 2004;27(5):1218-1224.

16. Adams AS, Trinacty CM, Zhang F, et al. Medication adherence and racial differences in A1C Control. Diabetes Care. 2008;31(5):916-921.

17. Jamous RM, Sweukeg WM, Abu-Taha AS, Sawalha AF, Zyoud SH, Morisky DE. Adherence and satisfaction with oral hypoglycemic medications: a pilot study in Palestine. Int J Clin Pharm. 2011;33:942-948.

18. Tiv M, Viel J-F, Mauny F, et al. Medication adherence in type 2 diabetes: The ENTRED Study 2007, a French population-based study. PLoS ONE. 2012;7(3):e32412.
19. Wong MC, Kong AP, So WY, Jian JY, Chan JC, Griffiths SM. Adherence to oral hypoglycemic agents in 26,782 Chinese patients: a cohort study. J Clin Pharmacol. 2011;51(10):1474-1482.

20. www.who.int [homepage on the internet]. Chronic diseases and health promotion. The STEPS Instrument and Support Materials. World Health Organisation; 2007 [cited January 4, 2013]. Available from: www.who. int/chp/steps/Part5.pdf. Accessed March 9, 2010.

21. Breitscheidel L, Stamenitis S, Dippel FW, Schoffski O. Economic impact of compliance to treatment with antidiabetes medication in type 2 diabetes mellitus; a review paper. $J$ Med Econ. 2010;13(1):8-15.

22. Ho PM, Rumsfeld JS, Masoudi FA, et al. Effect of medication nonadherence on hospitalisation and mortality among patients with diabetes mellitus. Arch Intern Med. 2006;166(17):1836-1841.

23. Hansen RA, Farley JF, Droege M, Maciejewski ML. A retrospective cohort of study of economic outcomes and adherence to monotherapy with metformin, pioglitazone, or a sulphonylurea among patients with type 2 diabetes mellitus in the United States from 2003-2005. Clin Ther. 2010;32(7):1308-1319.

24. Paes AH, Bakker A, Soe-Agnie CJ. Impact of dosage frequency on patient compliance. Diabetes Care. 1997;20(10):1512-1517.

25. van Bruggen R, Gorter K, Stolk RP, Zuithoff P, Klungel OH, Rutten GE. Refill adherence and polypharmacy among patients with type 2 diabetes in general practice. Pharmacoepidemiol Drug Saf. 2009;18(11):983-991.

26. Kim N, Agostini JV, Justice AC. Refill adherence to oral hypoglycemic agents and glycemic control in veterans. Ann Pharmacother. 2010; 44(5):800-808.

27. Aikens JE, Piette JD. Longitudinal association between medication adherence and glycemic control in type 2 diabetes. Diabet Med. 2013; 30(3):338-344.

28. Quah JH, Liu YP, Luo N, How CH, Tay EG. Younger adult type 2 diabetic patients have poorer glycemic control: a cross-sectional study in a primary care setting in Singapore. BMC Endocr Disord. 2013;13(18).

29. Lau DT, Nau DP. Oral antihyperglycaemic medication nonadherence and subsequent hospitalisation among individuals with type 2 diabetes. Diabetes Care. 2004;27(9):2149-2153.

30. Haupt D, Weitoft GR, Nilsson JL. Refill adherence to oral antihyperglycaemic drugs in Sweden. Acta Diabetol. 2009;46(3):203-208.

31. Geisel-Marbaise S, Stummer H. Diabetes adherence - does gender matter? J Public Health. 2010;18(3):219-226.

32. Raum E, Heike UK, Ruter G, et al. Medication nonadherence and poor glycaemic control in patients with type 2 diabetes mellitus. Diabetes Res Clin Pract. 2012;97(3):377-384.

33. Borgsteede SD, Westerman MJ, Kok IL, Meeuse JC, de Vries TP, Hugtenburg JG. Factors related to high and low levels of drug adherence according to patients with type 2 diabetes. Int J Clin Pharm. 2011;33(5): 779-787.

34. Donnan PT, MacDonald TM, Morris AD. Adherence to prescribed oral hypoglycaemic medication in a population of patients with type 2 diabetes: a retrospective cohort study. Diabet Med. 2002;19(4): 279-284.

35. Davis-Ajami ML, Nahata MC, Reardon G, Seiber EE, Balkrishnan R. Associations between joblessness and oral anti-diabetic medication adherence in US Diabetic Working-Age adults. Health Outcomes Res Med. 2012;3(3):e140-e151.

36. Patel I, Chang J, Shenolikar RA, Balkrishnan R. Medication adherence in low income elderly type 2 diabetes patients: a retrospective cohort study. Int Journal of Diabetes Mellit. 2010;2(2):122-124.

37. Ahmad NS, Islahudin F, Paraidathathu T. Factors associated with good glycemic control among patients with type 2 diabetes mellitus. J Diabetes Invest. Epub 2013 Dec 5.

38. Rwegerera GM. Adherence to anti-diabetic drugs among patients with type 2 diabetes mellitus at Muhimbili National Hospital, Dar es Salaam, Tanzania - A cross-sectional study. Pan Afr Med J. 2014;17:252.

39. Nagrebetsky A, Griffin S, Kinmonth AL, Sutton S, Craven A, Farmer A. Predictors of suboptimal glycaemic control in type 2 diabetes: the role of medication adherence and body mass index in the relationship between glycaemia and age. Diabetes Res Clin Pract. 2012;96(2): $119-128$. 
40. Al-Qazaz HKh, Sulaiman SA, Hassali MA, et al. Diabetes knowledge, medication adherence and glycaemic control among patients with type 2 diabetes. Int J Clin Pharm. 2011;33(6):1028-1035.

41. Yusuff KB, Obe O, Joseph BY. Adherence to antidiabetic therapy and self- management practices among type 2 diabetics in Nigeria. Pharm World Sci. 2008;30(6):876-883.

42. Chuang LM, Tsai ST, Huang BY, Tai TY; Diabcare-Asia 1998 Study Group. The status of diabetes control in Asia- a cross-sectional survey of 24,317 patients with diabetes mellitus in 1998. Diabet Med. 2002; 19(12):978-985.

43. Martin FI. The clinical characteristics of diabetes mellitus in Papua New Guinea. P N G Med J. 1978;21(4):317-322.

44. Savige J, Martin FI. Mortality and morbidity of diabetes in Papua New Guinea. Diabetologia. 1982;23(2):136-137.
45. Diabetes.niddk.nih.gov [homepage on the Internet]. National Diabetes Statistics 2011. National Institute of Diabetes and Digestive and Kidney Disease. [cited 2013 December 15]. Available from: diabetes.niddk. nih.gov/dm/pubs/statistics/DM_statistics_508.pdf. Accessed July 16, 2013.

46. Hankó B1, Kázmér M, Kumli P, et al. Self-reported medication and lifestyle adherence in Hungarian patients with type 2 diabetes. Pharm World Sci. 2007;29(2):58-66.

47. Sankar UV, Lipska K, Mini GK, Sarma PS, Thankappan KR. The adherence to medications in diabetic patients in rural Kerala, India. Asia Pac J Public Health. Epub 2013 Feb 14.

\section{Publish your work in this journal}

Patient Preference and Adherence is an international, peer-reviewed, open access journal that focuses on the growing importance of patient preference and adherence throughout the therapeutic continuum. Patient satisfaction, acceptability, quality of life, compliance, persistence and their role in developing new therapeutic modalities and compounds to optimize clinical outcomes for existing disease states are major areas of interest for the journal. This journal has been accepted for indexing on PubMed Central. The manuscript management system is completely online and includes a very quick and fair peer-review system, which is all easy to use. Visit http://www. dovepress.com/testimonials.php to read real quotes from published authors.

\footnotetext{
Submit your manuscript here: http://www.dovepress.com/patient-preference-and-adherence-journal
} 